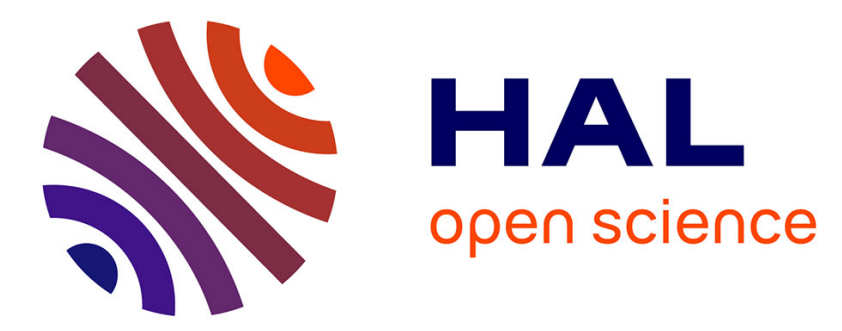

\title{
A new method for the study of parabolic impact of foam-core sandwich panels
}

Karthik Ram Ramakrishnan, Sandra Guérard, Laurent Mahéo, Krishna Shankar, Philippe Viot

\section{To cite this version:}

Karthik Ram Ramakrishnan, Sandra Guérard, Laurent Mahéo, Krishna Shankar, Philippe Viot. A new method for the study of parabolic impact of foam-core sandwich panels. Composites Part B: Engineering, 2019, 167, pp.717-727. 10.1016/j.compositesb.2019.02.062 . hal-02115039

\section{HAL Id: hal-02115039 \\ https://hal.science/hal-02115039}

Submitted on 22 Oct 2021

HAL is a multi-disciplinary open access archive for the deposit and dissemination of scientific research documents, whether they are published or not. The documents may come from teaching and research institutions in France or abroad, or from public or private research centers.
L'archive ouverte pluridisciplinaire HAL, est destinée au dépôt et à la diffusion de documents scientifiques de niveau recherche, publiés ou non, émanant des établissements d'enseignement et de recherche français ou étrangers, des laboratoires publics ou privés.

\section{다)(1) $(5$}

Distributed under a Creative Commons Attribution - NonCommercial| 4.0 International 


\section{A new method for the study of parabolic impact of foam-core}

\section{sandwich panels}

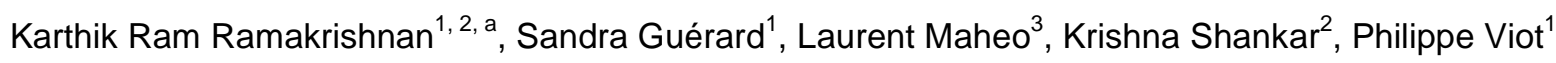

${ }^{1}$ Arts et Métiers ParisTech, I2M, CNRS UMR 5295, F-33405 Talence, France

${ }^{2}$ University of New South Wales, Canberra, ACT 2600, Australia

${ }^{3}$ Univ Bretagne Sud, UMR CNRS 6027, IRDL, F-56321 Lorient, France

${ }^{a}$ Current affiliation: Department of Engineering Science, University of Oxford, OX1 3PJ, Oxford, UK

\section{Abstract}

Lightweight sandwich panels with composite facesheets and foam core have high impact energy absorption capability and are widely employed in multifunctional applications such as aircraft and marine structures. The dynamic behaviour of sandwich panels is typically studied for impact loading at normal angle of incidence but the structures are more frequently loaded at some oblique angle or with a complex tri-dimensional trajectory in real engineering situations. The damage area and damage modes for these trajectories are significantly different and it is not sufficient to study only normal impacts. There are well established experimental protocols for normal or oblique impact tests using devices like the drop tower, but impacts with complex trajectory are difficult to characterise experimentally. In this paper, a Gough-Stewart platform with six degrees of freedom has been modified to develop an original tri-dimensional impact device called Hexapod. The trajectory is defined to an impactor attached to the seventh jack of the Hexapod to study the response of sandwich plates to impact loading with complex trajectories. The applicability of the newly developed device is demonstrated by studying parabolic impact with different trajectories on sandwich plates with Kevlar facesheets and Rohacell foam core. The time history of vertical and horizontal components of force is measured using tri-axial load cell and strain history is obtained from Digital Image Correlation of a high speed camera images. The results of the parabolic impact show the importance of shear behaviour of the foam in the progression of damage in the sandwich panels. Additionally, the response of the sandwich panels to parabolic impact was simulated numerically using explicit finite element code LS-DYNA. The results of the FE model are compared with experimental data in terms of the force history and strain contours. 


\section{Introduction}

Sandwich composites with fibre reinforced plastic (FRP) facesheets have emerged as a major class of lightweight structural materials in a wide range of engineering fields including aerospace, automotive, locomotive, building, wind energy and marine structures. The impact performance of sandwich structures has been identified as being of considerable importance [1] and it has been noted that sandwich structures must dissipate the impact energy to protect either the rest of the structure or humans during impact loads. However, some sandwich composites have been shown to be vulnerable to damage caused by impact [2]. Most previous studies on low velocity impact damage used drop weight experimental methods of a relatively large mass, which represented the accidental damage caused by dropped tools [3]. The impact loading is applied along one fixed direction that is perpendicular to the plane of the sandwich specimen and the response of the panels are analysed in terms of peak load, absorbed energy and deflection at peak load [4]. However, Ivanez et al. [5] noted that normal impacts rarely occur in real engineering situations. Instead, the structures are more frequently loaded at some oblique angle or complex trajectory such as collision with floating or submerged objects and low-speed berthing impacts [6] or lateral collisions in bridge [7]. The investigation of behaviour of sandwich composite to dynamic multi-axial loading is of great importance as in-service loading conditions are often multi-axial due to the complex geometries of structures and intricate loading conditions [8]. Navarro et al. [9] found that the damage mechanisms of the facesheet, the shape of the fracture surface and the tearing energy threshold of sandwich composites were highly influenced by the angle between the firing axis and the orientation of the fibres in oblique impacts. In an extensive review of publications on low velocity impact of sandwich structures, it was reported that most of the studies on sandwich panels subjected to low velocity impact were for normal impacts and studies of angles other than perpendicular to the plane of the sandwich were limited [2]. Birman and Kardomateas [10] concluded in their recent review that impacts at an angle may prevent the realization of some of the failure modes and that it would be interesting to expand the study of impact response of sandwich composites to oblique impacts. Ivanez et al. [5] analysed the influence of the impact angle on the main impact parameters and damaged area of the core for composite sandwich structures with carbon/epoxy face-sheets, and a Nomex honeycomb core at four different impact angles: $0,5,10$ and $15^{\circ}$. Zhou et al. [11] observed that increasing the angle of incidence resulted in an increase of the perforation energy and found that in the case of an oblique impact, the 
impact energy is dissipated in shearing both the composite and the foam around the perimeter of the projectile, as well as crushing the foam ahead of the impactor. The shear fracture properties of the foams had a significant effect on the perforation resistance of the sandwich structures and this mode of failure cannot be neglected [11]. It was also found that the debonding in the interface between the facesheets and the core of sandwich panels is predominated by a sliding mode and more critical debonding was observed in oblique impacts due to low relative density of the core [12]. Foam breakage and the interface debonding were indicated through the impact damage of the sandwich composite under transverse impact [13]. Therefore, it is imperative that the impact test method replicates the expected in-service impact events and as such there are no standardised test methods for impact testing of sandwich composites with complex trajectories. Typically, devices such as the drop tower are used to conduct impact tests at normal incidence, while other trajectories are more difficult to undertake with the same device, given the need to guide the projectile, coupled with the presence of a horizontal force component on the required guide rails. In order to overcome this difficulty, a tri-dimensional impact device called Hexapod was first proposed by Guérard et al. [14] to experimentally study the impact loading of sandwich plates with a parabolic trajectory. The three dimensional impact testing of sandwich samples made of Aluminium facesheets and PVC closed-cell foam (Divinycell) core was demonstrated using the Hexapod setup by Guérard et al. [14] and Ramakrishnan et al. [15]. Sandwich samples with two different thicknesses of the 2024 aluminium facesheets: $0.5 \mathrm{~mm}$ and $1 \mathrm{~mm}$ were considered. The PVC foam core had a 20-mm thickness. The sandwich panels were assembled using a two-component epoxy adhesive (Araldite AW 106R/hardener HV 953U) which was chosen for their high shear and peel strength. Sandwich plates with metallic facesheets were investigated but a proper study of sandwich plates with laminated composite facesheets subjected to parabolic impact has not been undertaken. Similarly, the effect of impactor shape on the parabolic impact response of the sandwich panel has not been done though Kursun et al. [16] studied conical, ogival, hemispherical and flat bottom shape indenters in drop weight tests.

Extensive experimental testing is not always practical as it requires expensive ancillaries such as high speed cameras and do not provide adequate information about the effect of a wide range of variables as these tests provide response data for particular plate and loading conditions. Further, predicting the response of sandwich plates is complicated due to effects such as material and geometric 
nonlinearities, transverse shear effects and multiple and coupled damage modes [17]. These problems and cost of experimentation can be reduced by supplementing experimental tests with numerical analyses, which can help in predicting the energy absorption and peak loads for a given combinations of materials and geometry by considering competing mechanisms[18], [19], [20], [21], [22]. It is possible to utilise continuum modelling techniques to numerically simulate the impact response of sandwich composites due to the increased accuracy of available constitutive models and improved computational power. Chen et al. [23] developed a methodology based on knowledge of the constitutive behaviour of each of the constituents of the sandwich, namely, the core, facesheets, and bond layers to predict the response of foam- core sandwich composites to low velocity impact. Rajaneesh et al. [19] developed a numerical simulation of sandwich plates with a core made of aluminium alloy foam with faceplates made of either aluminium or carbon fibre reinforced plastic (CFRP) using3D finite element models in LS-DYNA. It was shown that a finite element (FE) analysis provides the capability to model the impact event, including the complex internal damage mechanisms in a relatively short time and can help in predicting the energy absorption and peak loads for a given combinations of materials and geometry. The contribution of the individual elements of the sandwich panel to the energy absorption can also be obtained. Pascal et al. [24] showed that the local damage phenomena in the composite facesheets due to medium velocity oblique impacts of foam core sandwich plates can be represented with an FE model. It is important to validate the FE model with qualitative and quantitative comparison to specific experimental results before the model can be used for wider application in the design process.

This article is focussed on the study of parabolic impact testing of sandwich plates with laminated composite facesheets and foam core using a combination of Hexapod testing and finite element modelling. The experimental setup used for the parabolic impact is described in the next section. The effect of the impactor shape on the force-response of the Kevlar Rohacell sandwich plate is studied. An LS-Dyna model of the sandwich is then used to simulate the parabolic impact case.

\section{Materials and methods}

\subsection{Materials and manufacturing of sandwich panels}

Kevlar129 (Saatilar Style 802; Taffeta $190 \mathrm{~g} / \mathrm{m}^{2}$; thickness: $260 \mu \mathrm{m}$ ) was chosen as the fibre reinforcement of the FRP facesheets due to its very high tensile toughness $\left(\sigma_{r}=3.4 \mathrm{GPa}, \varepsilon_{r}=3.5 \%\right)$. 
Three layers of plain woven fabric with the ply orientation [0/90] were used. The diglycidyl ether of bisphenol A (DGEBA) thermoset epoxy resin Epolam 2020 and hardener supplied by Axson Technologies was chosen as matrix material. Closed cell PolyMethacryllmide (PMI) foam commercially available as Rohacell was chosen as the core material for the sandwich panels. Rohacell foam is available in different densities and thickness, and a foam with density of $51 \mathrm{~g} / \mathrm{cm}^{3}$ and thickness of $20 \mathrm{~mm}$ was chosen for our study. Parabolic impact tests were conducted on sandwich plates with Kevlar facesheets and Rohacell foam core (referred as KR sandwich) manufactured using a wet layup method and co-cured in a hot press at $90^{\circ} \mathrm{C}$ for 90 minutes. Cocuring the facesheets ensured good adhesion with the core. Finally, the sandwich composites were post-cured in an oven at $80^{\circ} \mathrm{C}$ for 2 hours.

\subsection{Experimental setup for parabolic impact testing of sandwich panels}

Low velocity parabolic impact tests were conducted in the Dynamics platform of Durability of Materials, Assemblies and Structures Department of I2M laboratory in Arts et Métiers ParisTech, France. The impact tests were conducted using the Hexapod shown in Figure 1. The Hexapod is a modified version of a parallel robot called Gough-Stewart platform. It is made of a fixed base and a mobile platform connected by six "feet" that can be controlled independently, allowing three translation and three rotation degrees of freedom. The maximum horizontal velocity and vertical velocity that can be reached by the Hexapod are $1.4 \mathrm{~m} / \mathrm{s}$ and $1 \mathrm{~m} / \mathrm{s}$, respectively. Additionally, a seventh electromechanical jack is attached to the mobile platform. The maximum velocity of the seventh jack is $3.5 \mathrm{~m} / \mathrm{s}$, thereby increasing the vertical speed range of the Hexapod. The range of velocities achieved with this configuration of Hexapod is equivalent to the drop tower but with the advantage of imposing a $3 \mathrm{D}$ trajectory to the projectile [14]. The impactor and a tri-axial load cell (Kistler, 9377C) are attached to the bottom end of the seventh jack. The measurement range of the tri-axial load cell in the horizontal (Fx and Fy) and vertical (Fz) directions is $3000 \mathrm{~N}$ and $5000 \mathrm{~N}$ respectively. The steel cylindrical impactor has diameter of $50 \mathrm{~mm}$ and length of $120 \mathrm{~mm}$. The cylindrical impactor attached to the Hexapod can be easily swapped with other geometries such as wedge-shaped impactor. Two wedge shaped impactors with angles $60^{\circ}$ and $120^{\circ}$ are also used to study the effect of the impactor geometry on the impact behaviour of the sandwich plate. 


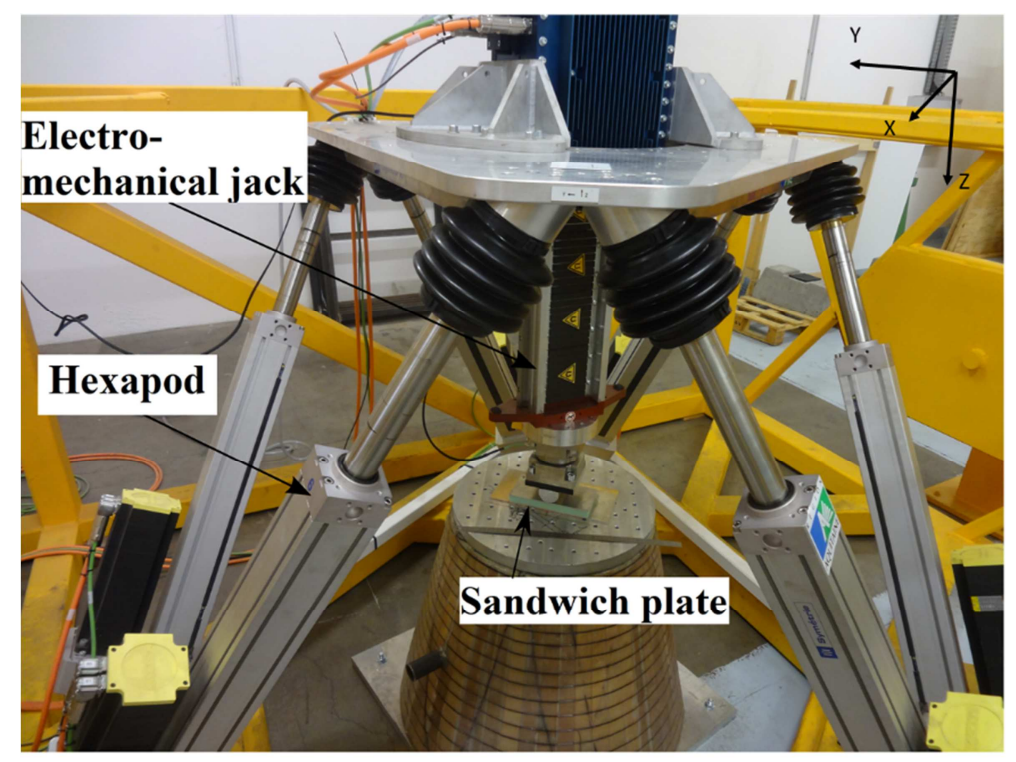

Figure 1 Hexapod setup for tri-dimensional impact of sandwich panels

Figure 2 shows the Hexapod setup for the parabolic impact of Kevlar Rohacell sandwich plates. The dimensions of the sandwich samples were $200 \mathrm{~mm}$ long and $120 \mathrm{~mm}$ wide. Figure 2(b) shows the clamping mechanism for the sandwich plate. The sandwich plate was bonded to an aluminium sheet approximately $300 \mathrm{~mm}$ long and $180 \mathrm{~mm}$ wide using an Araldite adhesive. A set of three jaws strategically placed at different points on the rigid base were used to clamp the aluminium sheet and to prevent the movement of the Kevlar sandwich plate during the impact. There were no other lateral constraints on the sandwich plate. A Photron Fastcam APX RS high-speed camera was used to film the impact at acquisition rate of 5000 frames per second. The side of the tested sandwich sample was coated with a fine spray of paint to create a random speckled pattern for Digital Image Correlation (DIC). DIC analysis of the high speed camera images were conducted using VIC-2D software from Correlated Solutions. The 3D load cell located between the impactor and the jack extremity was used to measure the horizontal and vertical components of force, at an acquisition frequency of $100 \mathrm{kHz}$. 


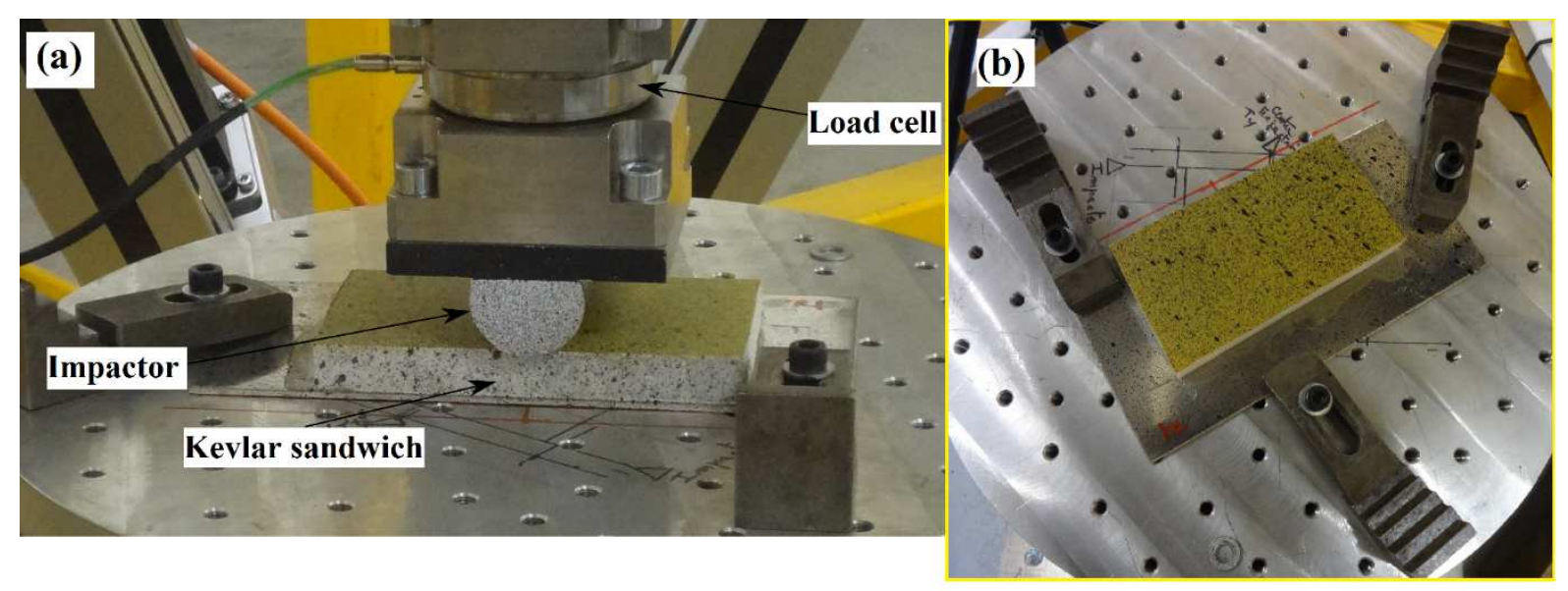

Figure 2 (a) Hexapod setup with cylindrical impactor and Kevlar-Rohacell sandwich, (b) Clamping mechanism

In the case of a normal impact using a drop tower, the impactor is raised to a particular height and the potential energy of the impactor is converted to kinetic energy when it is released. The displacement of the impactor is only in the $Z$-direction and the $X$ and $Y$ direction are constrained. A similar setup is used for oblique impact, where the displacement of the impactor is along the vertical axis but the sample is mounted at an angle. For a parabolic impact, the definition of the trajectory of the impactor is in terms of displacement curves in the $\mathrm{Y}$ - and Z- axis, corresponding to the horizontal and vertical directions. Figure 3 shows the displacement in the $\mathrm{Y}$ - direction and Z- direction, which is input to the hexapod. This represents the entire trajectory input to the impactor with three zones corresponding to the acceleration of the impactor before it comes into contact with the sandwich plate, the impact zone where the sample is loaded and a deceleration zone after the impact. The beginning of the contact with the sandwich target and the end of contact are represented by time $t_{0}$ and $t_{\text {end }}$, respectively. The vertical acceleration (along $Z$ direction) of the impactor at $t_{0}$ was equal to $4 \mathrm{~m} / \mathrm{s}^{2}$ and the horizontal velocity during impact (along $Y$ direction) was constant $(1 \mathrm{~m} / \mathrm{s})$. The parameters defining the impact are the depth of penetration into the impacted specimen $\left(z_{\max }\right)$ and the width or opening of the parabola $\left(\mathrm{y}_{\mathrm{end}}\right)$. In the parabolic displacement shown in Figure 3 a depth of penetration of $5 \mathrm{~mm}$ into the impacted specimen and a width of the parabola of $100 \mathrm{~mm}$ were imposed to the impactor. 


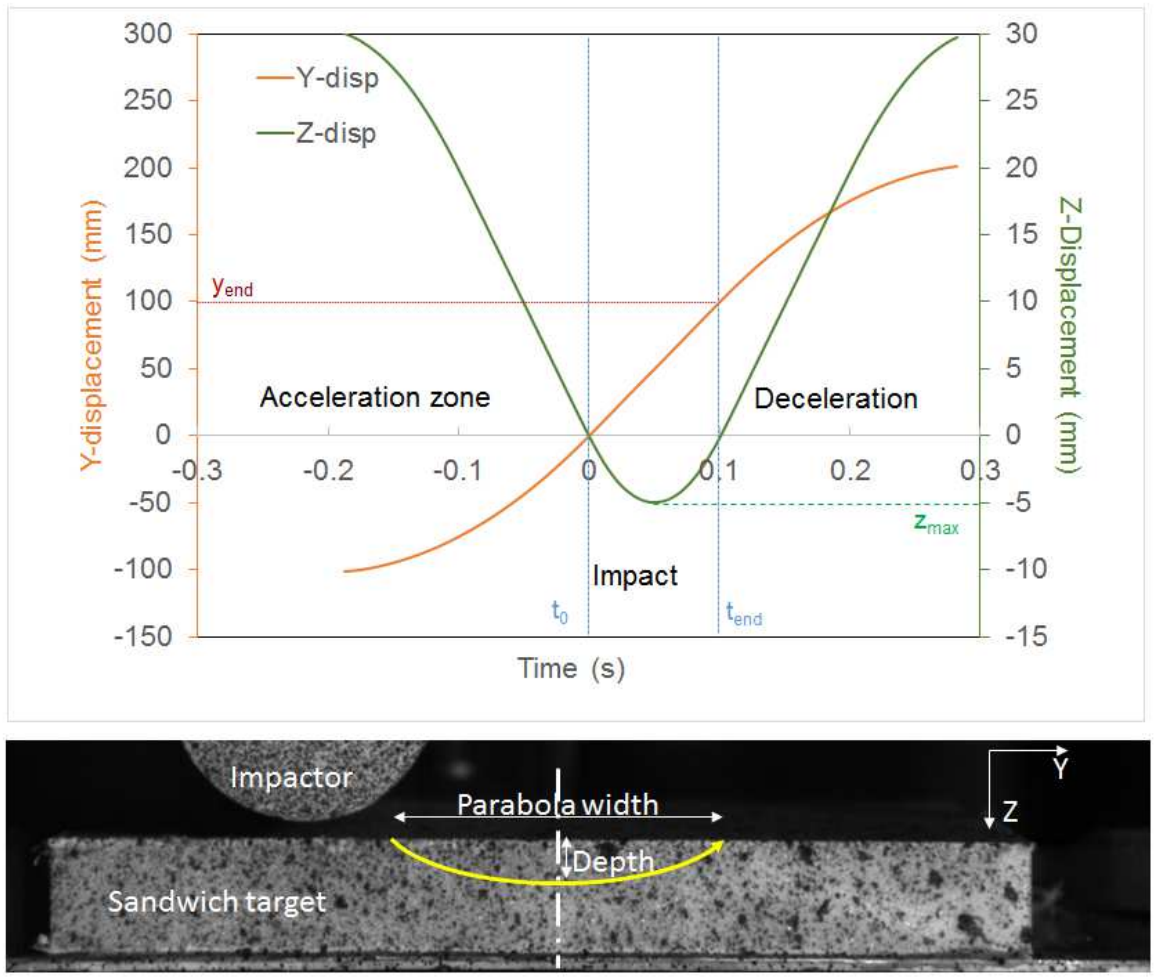

Figure 3 Typical parabolic trajectory for Hexapod impact and horizontal and vertical displacement input

A typical force- time history obtained from the tri-axial load cell is shown in Figure 4. This case corresponds to a parabola with maximum depth of penetration of $5 \mathrm{~mm}$ and an opening of $50 \mathrm{~mm}$. It can be seen that the vertical force (Z-force) is larger in magnitude than the horizontal component of force (Y-force or tangential force). The peak of the vertical force is about $2500 \mathrm{~N}$, while the peak of the horizontal force is approximately $1900 \mathrm{~N}$. The transverse force (X-direction) can be considered negligible compared to the vertical and horizontal force components. 


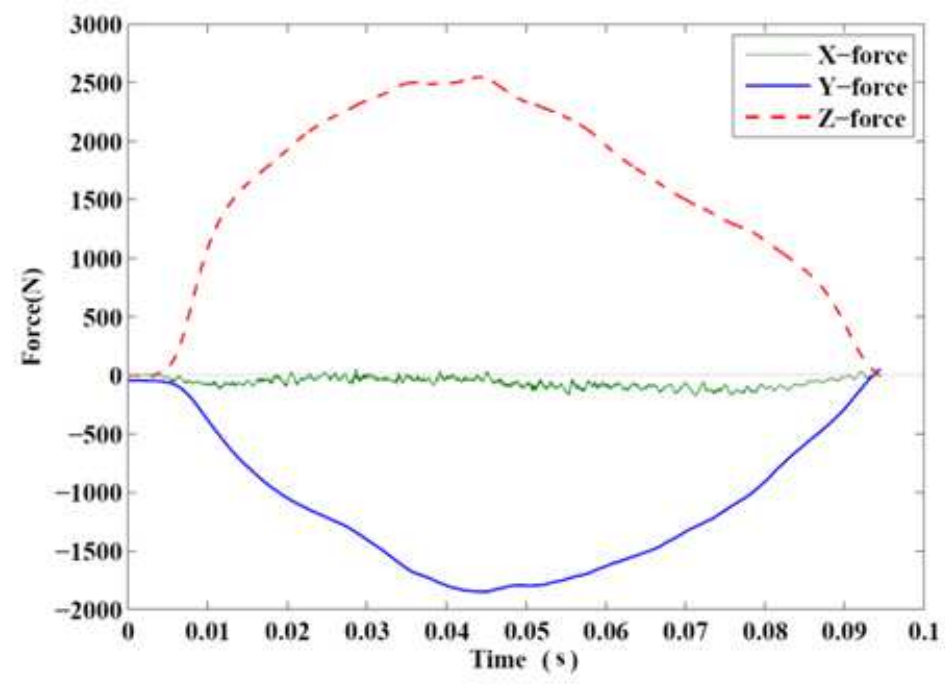

Figure 4 Typical Force- time results obtained for parabolic impact

\subsection{Parabolic trajectories for hexapod impact}

Two parabolic trajectories, named Traj1 and Traj2 were chosen for the hexapod impact with cylindrical impactor. The trajectory named Trajthas displacement in horizontal direction (Y-disp) of $100 \mathrm{~mm}$ (starting $25 \mathrm{~mm}$ right of the centre) and increasing linearly, while the displacement in Zdirection or thickness direction is a parabolic curve with a maximum depth of $5 \mathrm{~mm}$. The parabolic trajectory, named Traj2 corresponds to $\mathrm{Y}$ - displacement of $50 \mathrm{~mm}$ beginning from the same starting point. The displacement in the horizontal direction increases linearly, while the displacement in Zdirection is a parabolic curve with a maximum depth of $8 \mathrm{~mm}$. Traj2 is centred on the plate, i.e., the maximum displacement in the vertical direction coincides with the geometric centre of the plate. The parabolic trajectory corresponding to the contact period that is input to the Hexapod is shown in the Figure 5.It can be seen that the contact duration for the parabolic impacts is fixed and is about 90 to 100 milliseconds representing a prolonged contact with the sandwich panel, while the contact duration for the normal impact case in the drop tower is a function of the target plate and is typically of the order of 10 milliseconds. Since the behaviour of the sandwich samples were shown to be repeatable for the normal impact tests [4], only one sample of each type was tested for each configuration. 


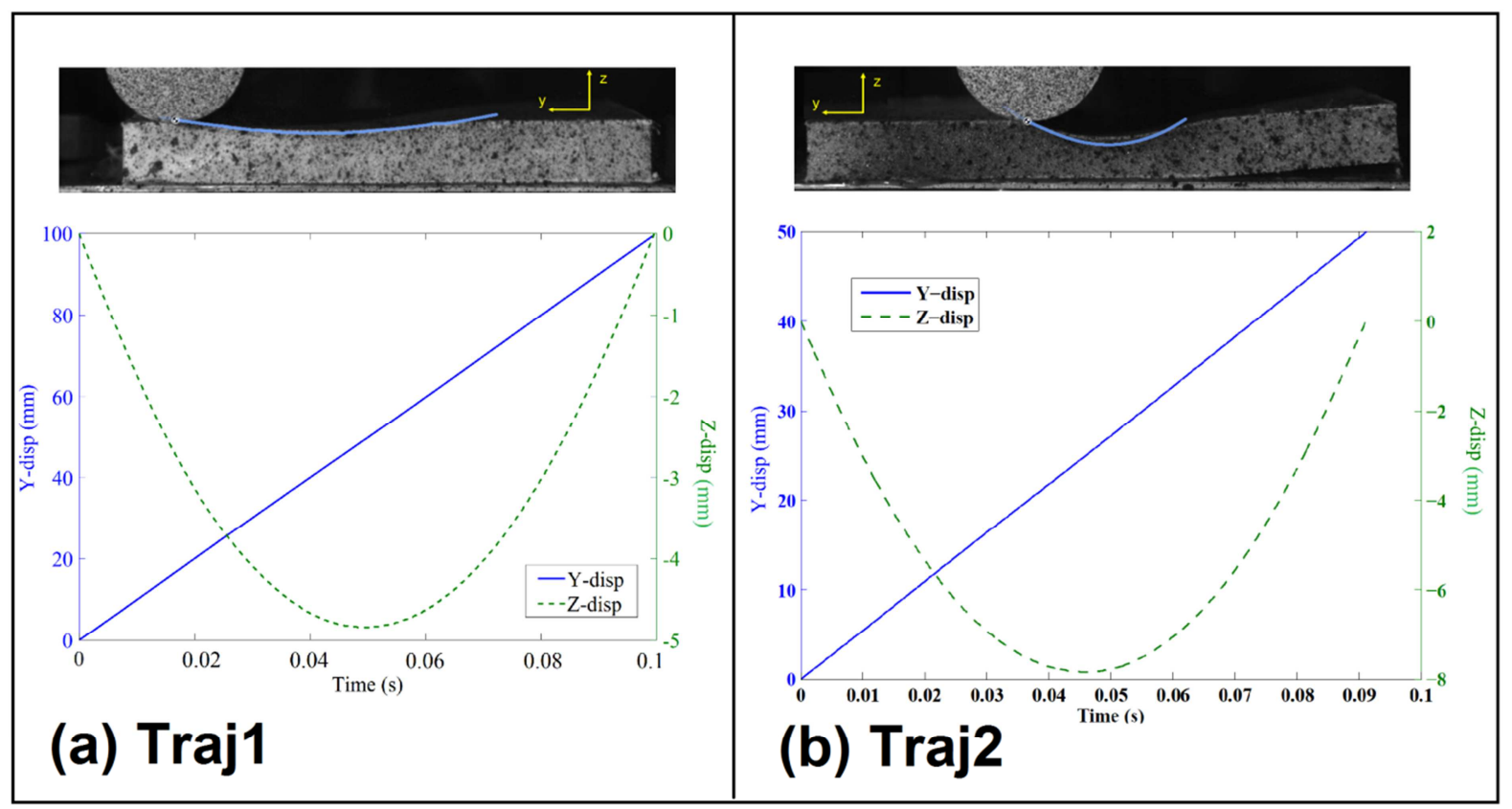

Figure 5 Parabolic trajectory input to the hexapod (a) Traj1 and (b) Traj2

\subsection{Development of FE model of parabolic impact of sandwich panels}

A numerical model of the parabolic impact of sandwich panels was developed using the finite element software, LS-Dyna. The sandwich plate was modelled with solid elements for the core and shell elements for the thin facesheets similar to the model described in [15] for Aluminium- Divinycell sandwich plates. The LS-Dyna model shown in the Figure 6 was created to simulate the parabolic impact of the Kevlar - Rohacell sandwich. The sandwich panels with the Kevlar fibre reinforced epoxy skins had a nominal thickness of $21.6 \mathrm{~mm}$, with a $20 \mathrm{~mm}$ thick Rohacell foam core and $0.8 \mathrm{~mm}$ thick facesheets on either side of the core. The dimensions of the plates were $200 \mathrm{~mm} \times 100 \mathrm{~mm}$. The foam core was modelled using constant stress brick elements. The 3 layered plain woven fabric with the ply orientation $[0 / 90]_{3}$ used for the facesheets were modelled with the keyword ${ }^{*} P A R T$ COMPOSITE. 


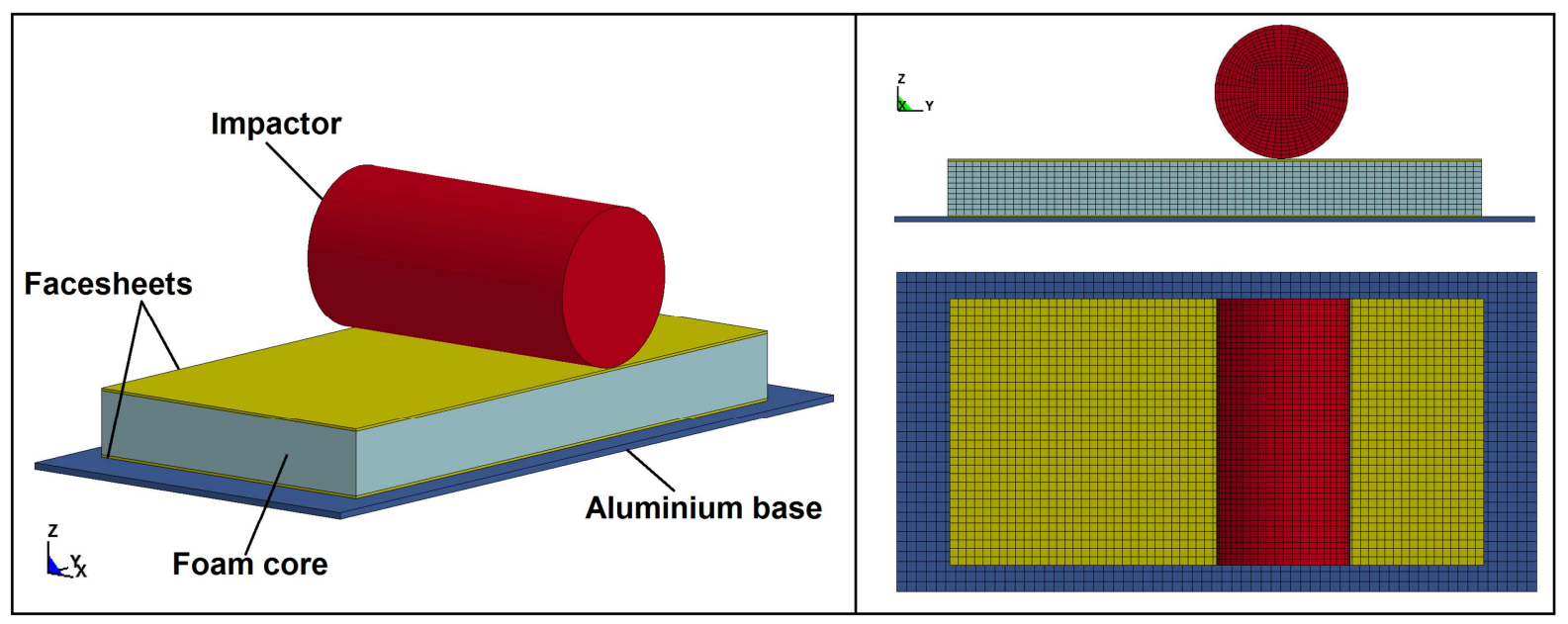

Figure 6 LS-Dyna model of Kevlar-Rohacell sandwich and cylindrical impactor

The material model for the Kevlar composite facesheets of the sandwich panels was Material 58 (LAMINATED COMPOSITE FABRIC material model) available in the LS-Dyna material model library. The elastic damage law chosen (MAT58) requires the identification of a set of input parameters. Three categories of parameters must be identified: i) the elastic properties of the material, ii) parameters related to damage and breakage, and iii) those related to behaviour after fracture. The material parameters for the Kevlar composite have been identified by tensile tests and 3-point bending tests. In addition to the elastic properties, the properties related to damage and breakage are described by maximum deformations and stresses. The important input parameters for the Kevlar composite facesheets are presented in Table 1. More details on the characterisation tests and the material parameters of the constitutive law are provided in our earlier publication [25]. 
Table 1 Material properties for Kevlar composite model

\begin{tabular}{|l|l|c|}
\hline Parameter & Method & Kevlar \\
\hline Young's Modulus in 0 and 90॰ & Tensile Test & $34.5 \mathrm{GPa}$ \\
\hline Shear Modulus (G12) & $45 \circ$ Tensile test & $2.96 \mathrm{GPa}$ \\
\hline Shear Modulus (G23, G31) & Flexure and Ultrasound & $4 \mathrm{GPa}$ \\
\hline Shear stress (T1) & $45 \circ$ Tensile test & $40 \mathrm{MPa}$ \\
\hline Shear strain (Y1) & $45 \circ$ Tensile test & 0.04 \\
\hline $\begin{array}{l}\text { Longitudinal and Transverse } \\
\text { Compressive strength (XC, YC) }\end{array}$ & From Literature[26] & $266 \mathrm{MPa}$ \\
\hline $\begin{array}{l}\text { Strain at Compressive strength } \\
\text { (E11C, E22C) }\end{array}$ & From Literature[26] & 0.0623 \\
\hline $\begin{array}{l}\text { Longitudinal and Transverse } \\
\text { Tensile strength (XT , YT ) }\end{array}$ & Tensile Test & $480 \mathrm{MPa}$ \\
\hline $\begin{array}{l}\text { Strain at Tensile strength (E11T } \\
\text { E22T ) }\end{array}$ & Tensile Test & 0.022 \\
\hline Shear strength (SC) & $45 \circ$ Tensile test \\
\hline Strain at shear strength (GMS) & $45 \circ$ Tensile test \\
\hline
\end{tabular}

The core and impactor are modelled with under-integrated constant stress hexahedral brick elements. MODIFIED CRUSHABLE FOAM MODEL MAT163 was chosen as the material model for the Rohacell foam core. Rohacell foam is an isotropic foam and it has been reported that compressive properties in the three mutually perpendicular directions show similar profile and magnitude [27]. The strain-rate dependent properties of the isotropic Rohacell foam were obtained from uniaxial compressive material tests conducted in three strain rates; corresponding to quasistatic tests conducted in Zwick Roell mechanical testing system at $5 \mathrm{~mm} / \mathrm{min}$, intermediate strain rate tests conducted in an inertial wheel system and high strain rate tests conducted in Split Hopkinson Pressure Bar. The compression properties at all the three strain rates are shown in Figure7. It can be seen that there is not a strong strain rate dependence on the compressive behaviour of the Rohacell foam. 


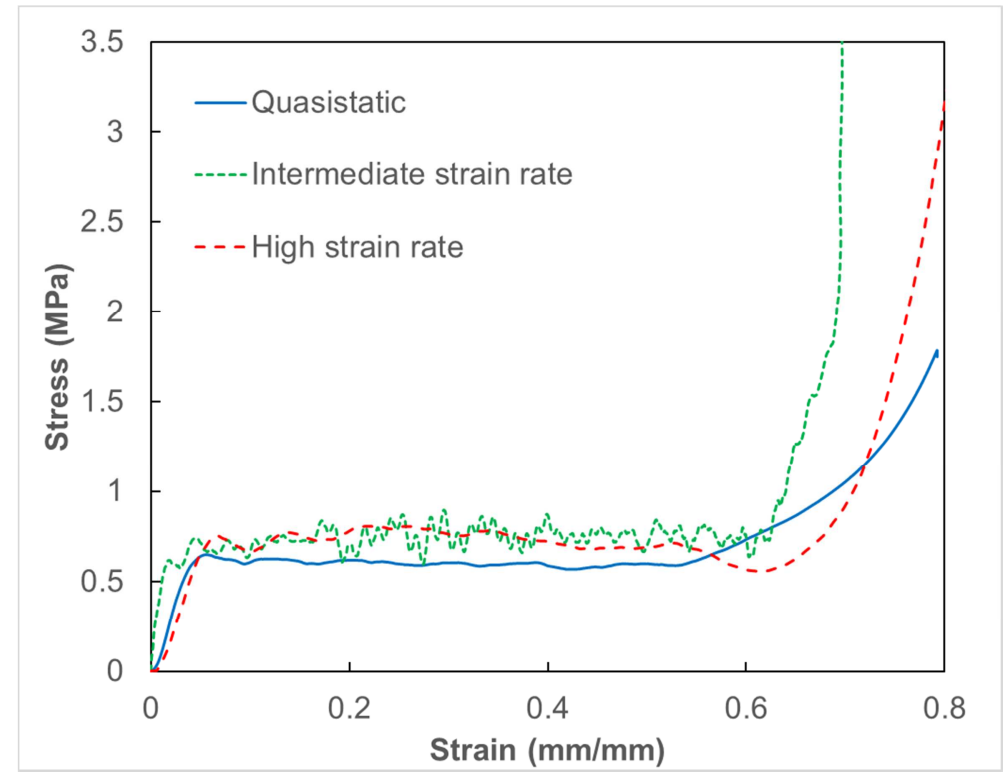

Figure 7 Uniaxial compression properties of Rohacell foam at different strain rates

There are several methods for modelling the failure of the adhesive bond between the facesheets and the core including using Tiebreak contacts and using Cohesive elements [28]. Surface to surface contact with TIEBREAK option was defined between the core and both the top and bottom facesheets to prevent the nodes in the facesheet and core parts from interpenetrating each other under compression. It is possible to examine the effect of debonding between the laminate layers using the failure criteria of the tiebreak contact. Failure is based on the forces or stress along the normal (tensile) and shear directions.

The total duration of the simulation is 90 milliseconds corresponding to the impact duration observed in the experiment. A fixed boundary condition was input to the aluminium support plate and a TIEBREAK contact was used to model a perfectly bonded contact between the sandwich plate and the support plate. There are no lateral constraints on the sandwich plate similar to the experimental setup and they are free to deform. The initial location of the impactor is $0.1 \mathrm{~mm}$ above the facesheet, i.e. just before the beginning of contact. In the case of the low velocity impacts with normal trajectory, an initial velocity is defined to the impactor but a displacement loading was used for the case of parabolic impact. The steel cylindrical impactor was given displacement input in the $\mathrm{Y}$ and $\mathrm{Z}$ direction by defining a curve to BOUNDARY PRESCRIBED MOTION keyword. It is possible to define different trajectories of the impactor using this option. A trajectory was chosen with the width of the parabola is $100 \mathrm{~mm}$ (starting from $25 \mathrm{~mm}$ to the right of the centre of the plate) and a depth of $5 \mathrm{~mm}$ (Traj1). This 
case was chosen for comparison with the experiment as the sandwich plate did not exhibit any shear failure in the core or debonding in the sandwich. The rotation motion of the cylindrical impactor was constrained and a friction constant of 0.3 was used between the impactor and the sandwich target. An influence of this friction parameter on the simulation results, particularly the tangential force was also investigated by varying the friction constant $(0.1,0.2,0.3)$. It can be seen from the force history in Figure 8 that the friction parameter has no appreciable effect on the normal force response but the tangential force is strongly influenced by the friction between the impactor and the sandwich plate. As the effect of friction constant is noticeable, its value will be adjusted using comparison between experiments and numerical simulation for Traj1 and cylindrical impactor. Moreover, it can be noticed that the friction constant has no effect on the contact duration.
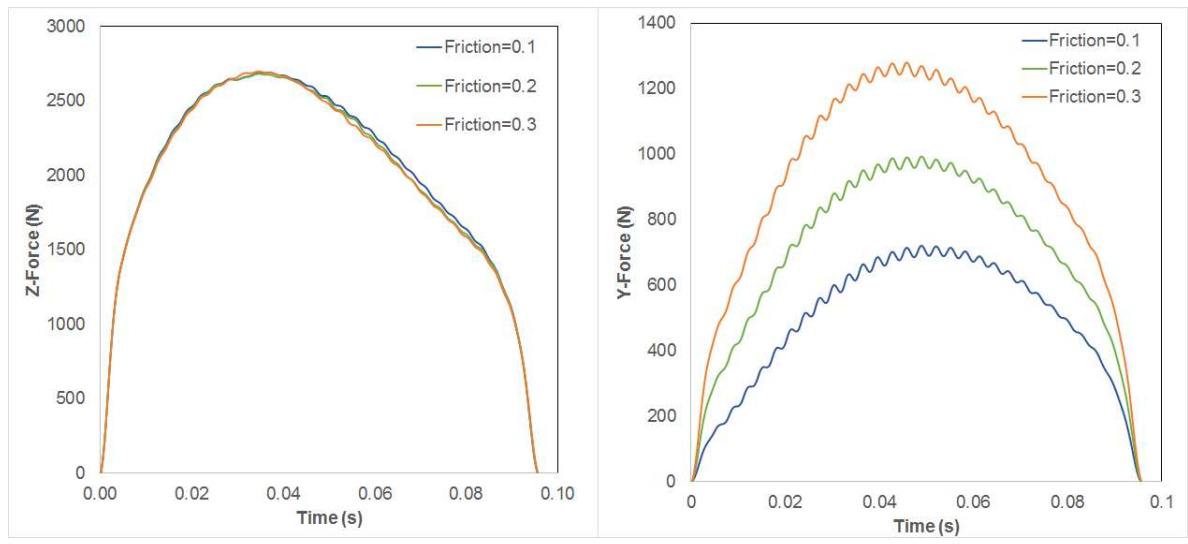

Figure 8 Effect of friction constant on the force history of impact simulation

\section{Effect of impactor shape:}

The effect of geometry of the impactors on the damage response of the sandwich plate was studied. The three impactors correspond to a cylindrical impactor with radius of $25 \mathrm{~mm}$, a wedge shaped impactor with wedge angle of $120^{\circ}$ and a sharp wedge impactor with angle of $60^{\circ}$ wedge.The comparison of the different impactors was accomplished for Traj2, i.e. opening of $50 \mathrm{~mm}$ and depth of $8 \mathrm{~mm}$. Figure 9 shows the trajectory of the parabola imposed to the hexapod that was input to the impactor in the FE model. The finite element mesh for the Kevlar sandwich plate with different impactor geometries is also shown in Figure 9. 

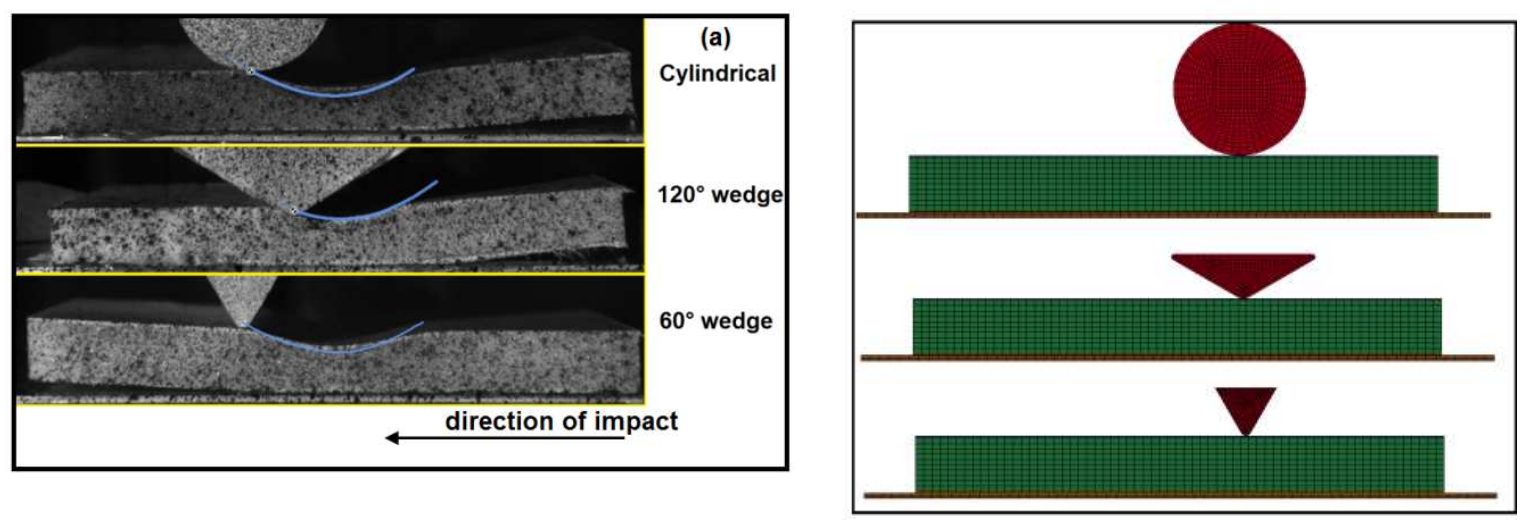

Figure 9 Parabolic trajectory with different impactor geometries - Cylindrical, $120^{\circ}$ and $60^{\circ}$ wedge: (a) experimental photos taken at the end of contact between impactor and specimen and (b) simulation configuration at the beginning of impact

\section{Results and discussion}

\subsection{Results of hexapod impact tests on Kevlar-Rohacell sandwich panels}

The progression of impact for the parabolic impact of KR sandwich with cylindrical impactor and Traj1 is shown in Figure 10. It can be seen that the impactor comes into contact with the sandwich plate at $\mathrm{t}=0 \mathrm{~ms}$; image (b) corresponds to $\mathrm{t}=22.5 \mathrm{~ms}$, which is immediately after the peak force is reached. The image (c) relates to the point of maximum z- displacement and the image (e) at $\mathrm{t}=90 \mathrm{~ms}$ is the end of the contact between the impactor and the sandwich target. In this case, the smaller value of depth was chosen to avoid any shear failure in the core or debonding in the sandwich. 


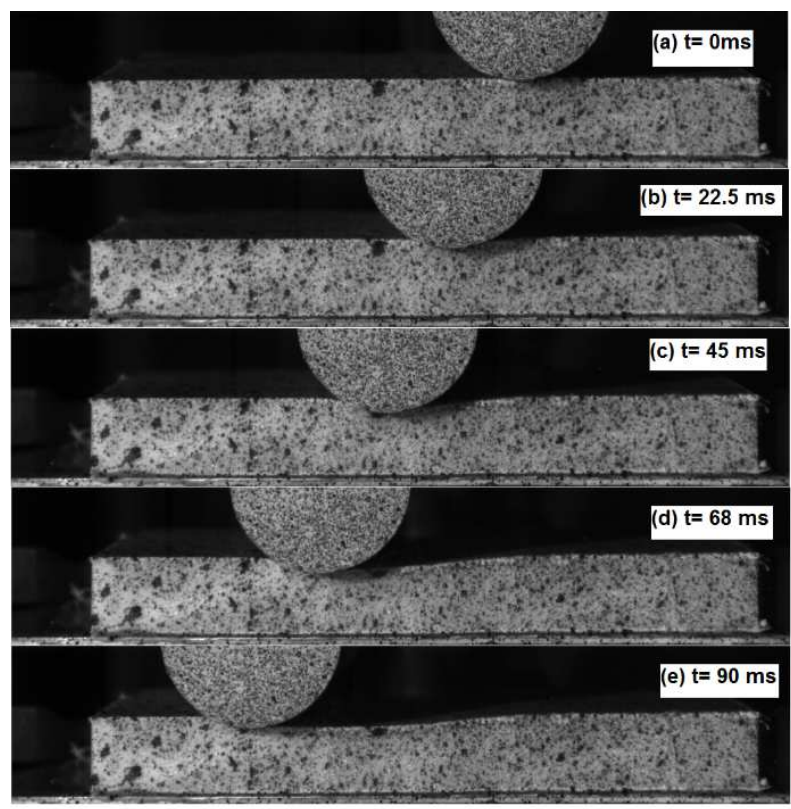

Figure 10 Progression of impact for KR sandwich from high-speed camera images (a)t=0ms, (b)t=22.5ms,

(c) $t=45 \mathrm{~ms},(\mathrm{~d}) \mathrm{t}=68 \mathrm{msand}(\mathrm{e}) \mathrm{t}=90 \mathrm{~ms}$ (the projectile shadow can be observed on the foam and should not be mixed up with deformed sandwich)

The impact response of the sandwich composite for Traj1 and Traj2 with cylindrical impactor was compared in Figure 11 showing the Force- time curve (a) for impact by cylindrical impactor for the two trajectories. The forces correspond to the vertical component of the force (Z-Force) and the horizontal component of the force (Y-force), with red colour representing Traj1 and green colour Traj2. It can be seen that the initial part of the force curves are very similar for the two trajectories. However, the damage observed in the two plates is different. Figure 11(b) and (c) shows the impacted sample of the KR sandwich panels for Traj1 and Traj2 respectively. It can be seen that there is shear damage in the foam core of the Traj2 sample, which results in the debonding between the bottom facesheet and the core. Even though the magnitude of the peak Z-force is similar for the two trajectories, the core damage causes the drop in the $\mathrm{Z}$ - force and the vertical force after $\mathrm{t}=45 \mathrm{~ms}$ (maximum displacement) is noticeably lower for the Traj2 sample. However, in the Traj 1 sample there is no core damage as the maximum depth of the trajectory was only $5 \mathrm{~mm}$. These results suggest that the overall response of the sandwich composite to parabolic impact is dominated by the core behaviour and not the facesheets. This is to be expected as the sandwich panel undergoes large shear deformation. 

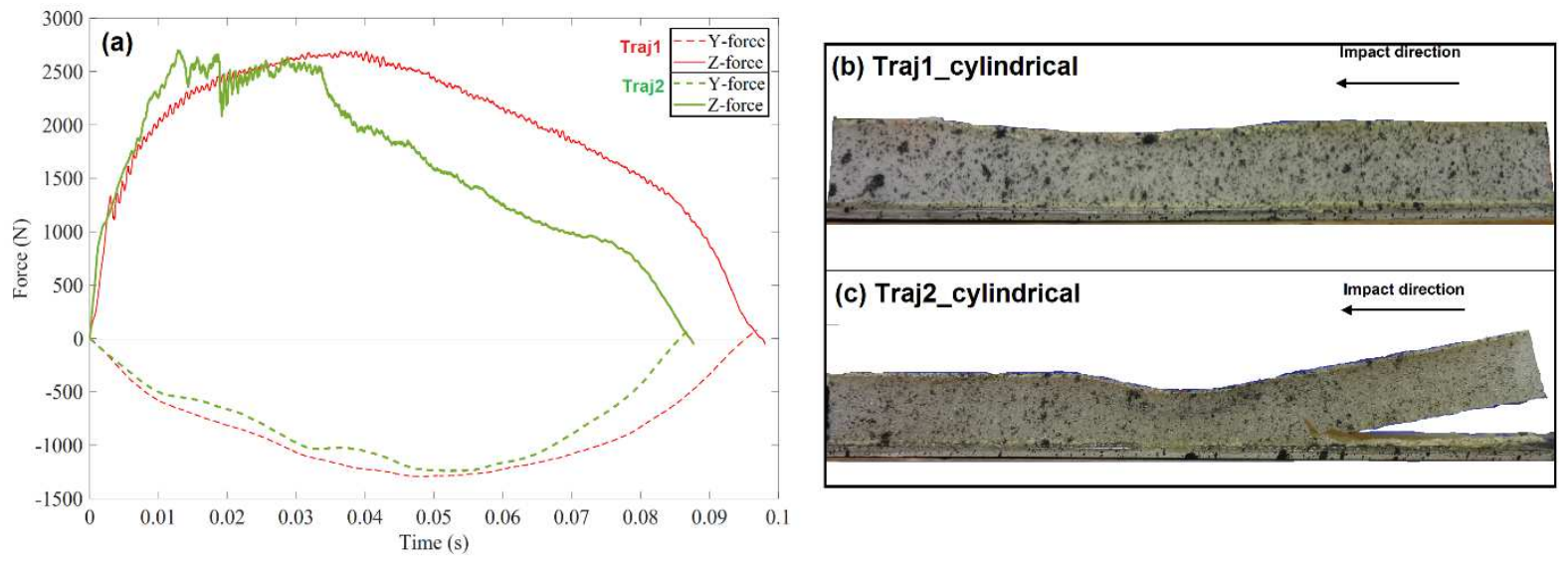

Figure 11 a) Force -time curve for impact by cylindrical impactor and $(b, c)$ KR sandwich samples after impact by cylindrical impactor for trajectory 1 and 2

The resultant force was calculated as $F_{\text {resultant }}=\sqrt{ }\left(F_{x}^{2}+F_{y}{ }^{2}+F_{z}{ }^{2}\right)$ and the force history for Traj1 impact is shown in Figure 12 (a). It can be seen that the $F_{\text {resultant }}$ is mainly dependent on the vertical force component but the peak force is increased due to the tangential component of the force. It is possible to calculate the work done in the sandwich panel due to the parabolic impact from the resultant forcedisplacement curve. The evolution of impact energy transferred from the Hexapod to the sandwich panel was also calculated as $W_{\text {impact }}=F_{\text {resultant }}{ }^{*} D_{\text {resultant }}$ and is shown in Figure 12 (b). It can be seen that the total work done as calculated from the area under the curve is $210 \mathrm{~J}$.

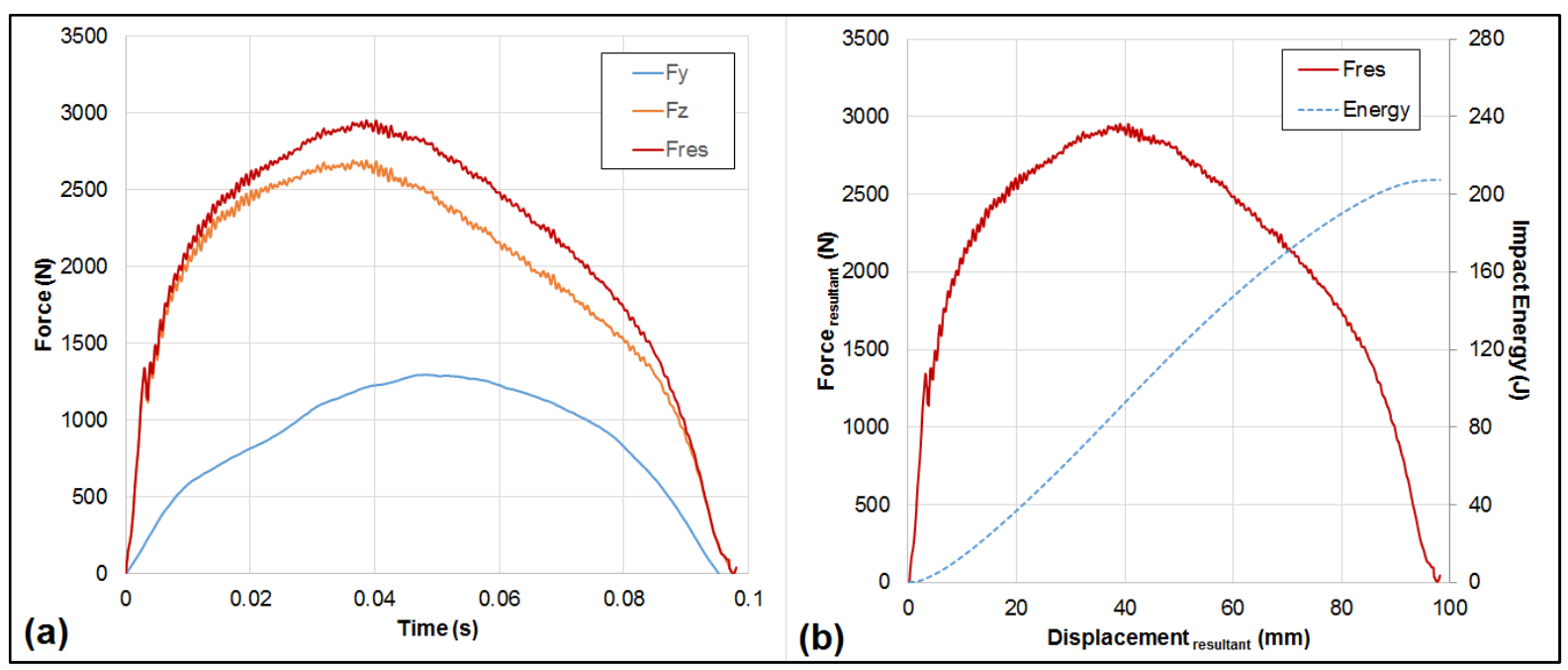

Figure 12 (a) Resultant force history, and (b) Evolution of energy transfer for Traj1 parabolic impact with cylindrical impactor

The calculation of the total energy absorbed by the sandwich is not as straightforward as in normal impact case. In the drop tower tests, the impactor has a mass and initial velocity from which the input kinetic energy and energy absorbed can be measured, but in hexapod tests a displacement trajectory 
is input and therefore the work done calculated from the resultant force-displacement curves is not reflective of the energy absorbed in the sandwich panel. However, the energy absorbed due to the normal component of the force is a good indicator of the behaviour of the sandwich plate. A comparison of the normal Force- displacement response for parabolic impact of KR sandwich plate with the three different impactor geometries is given in Figure 13. It can be seen that the initial linear region i.e., the stiffness of the plate at the beginning of the contact is nearly identical for the samples irrespective of the impactor geometry. The stiffness or slope changes for a Z-displacement of $0.5 \mathrm{~mm}$ and remains constant until the peak force is reached and a drop in force is observed. The sandwich panel recovers some of the vertical displacement during the unloading part of the trajectory. The energy absorbed in the sandwich plate measured from the area under the curve of the vertical force displacement history for the cylindrical, $120^{\circ}$ wedge and $60^{\circ}$ wedge impactors were $10.85,12.4$ and $7.02 \mathrm{~J}$.

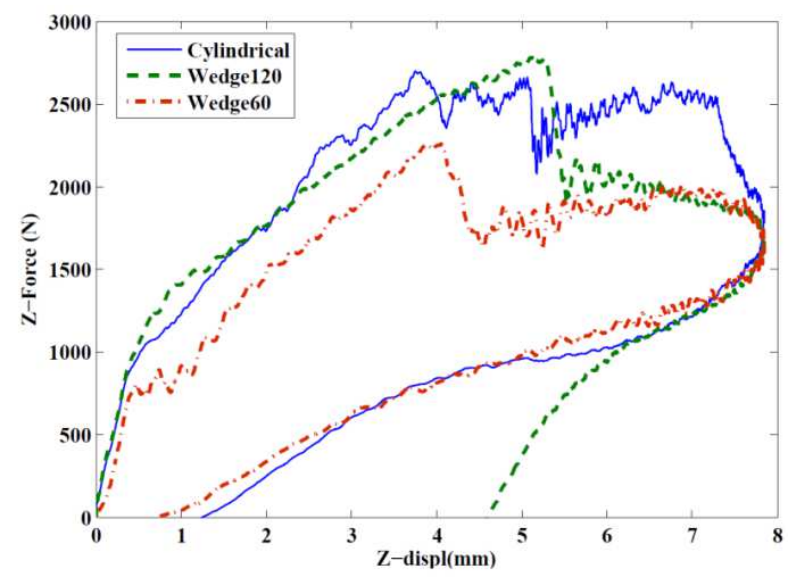

Figure 13 Comparison of Z- Force history for Kevlar-Rohacell sandwich with different impactor geometries -

Cylindrical, 120 and 60 wedge

The different failure modes observed in the experiment are shown in Figure 14. The failure in the KR sandwich panel is a combination of several modes with debonding between the core and the bottom facesheet occurring in some samples followed by shear failure in the core, whereas other samples show a debonding failure between the entire sandwich plate and the support plate and no shear failure. These failure modes are in contrast to the failure during drop tower impact tests presented in our earlier publication [4] which shows facesheet-dominant failure modes of fibre breakage, matrix microcracking and perforation, as well as core crushing in the foam core. This shows that the 
response of the sandwich composites to parabolic trajectory is different from the normal impact behaviour and bolsters the case for development of this hexapod testing methodology.
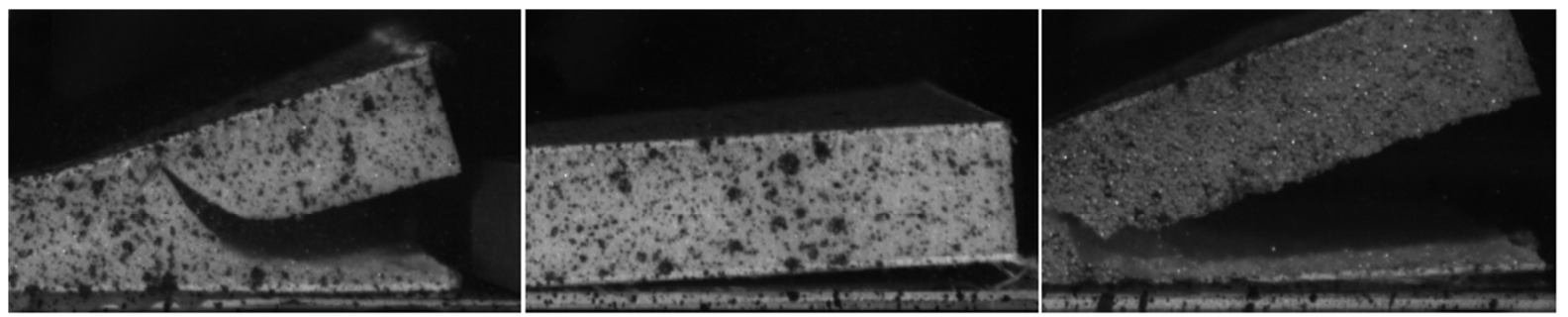

Figure 14 Failure modes in the sandwich panel after parabolic impact (Traj2) with cylindrical, wedge120 and

wedge60 impactors

\subsection{Results of LS-Dyna simulation for parabolic impact of Kevlar Rohacell sandwich}

The progression of effective strain in the core of the KR sandwich plate is shown in Figure 15. The case corresponds to cylindrical impactor and Traj1 trajectory. It can be seen that the cylindrical impactor comes into contact with the sandwich plate at Time $=0.45$ milliseconds and the entire width of the sandwich panel is loaded. The strain is initially limited to a small region of the sandwich plate and this region grows with increasing contact duration. The strain contour for contact time of 22.5, 45, and 90 milliseconds are also shown in the figure. The maximum strain reaches -0.55 under the impactor and at the end of the impact, elements along the length of the parabolic trajectory are crushed. It can also be seen that the core elements ahead of the impactor undergo deformation as well. 


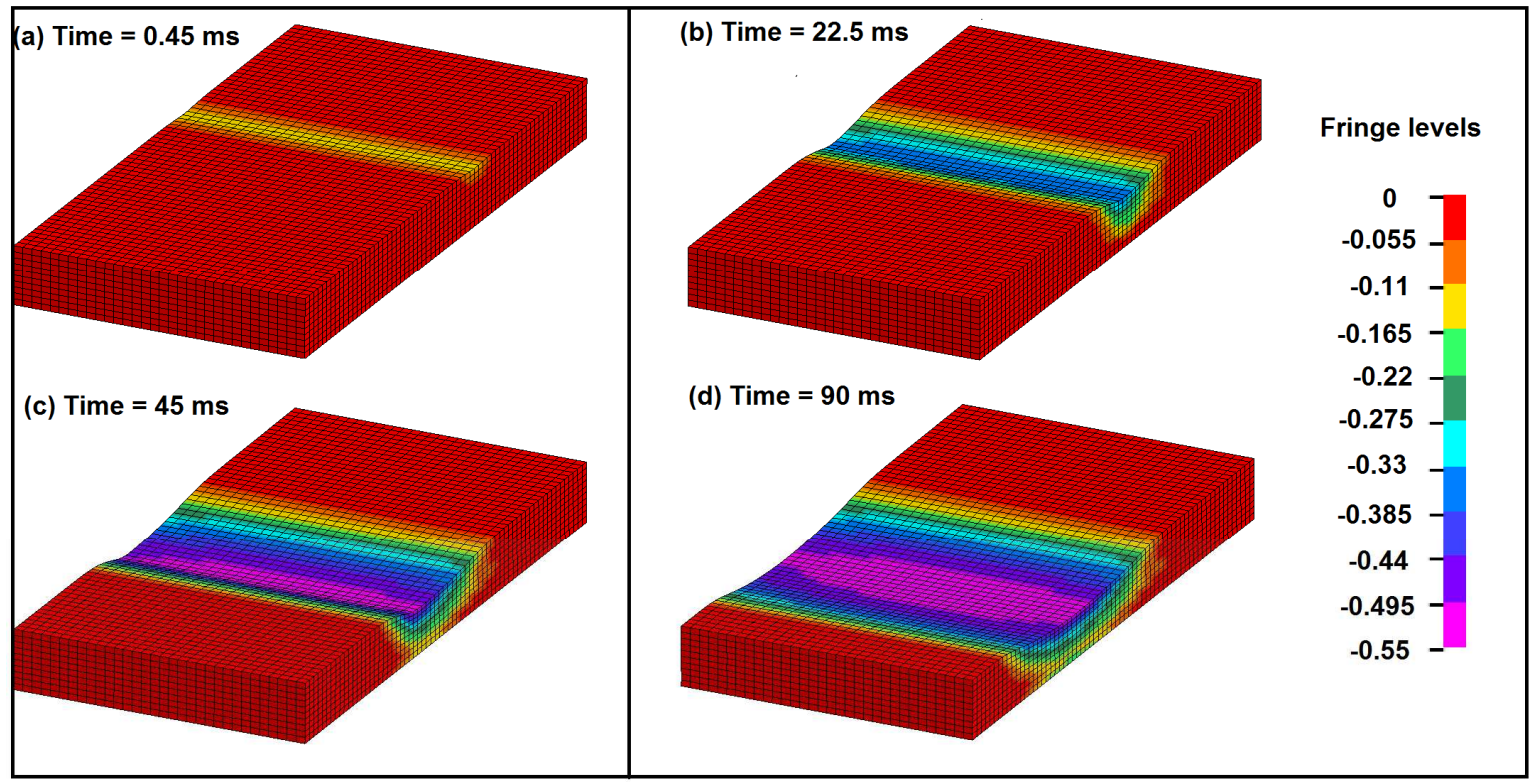

Figure 15 Progression of core effective strain for KR sandwich plate with cylindrical impactor and Traj1

The FE model is validated by a comparison of the horizontal and vertical components of the force for the parabolic impact of KR sandwich plate with a cylindrical impactor and Traj1, shown in Figure 16. The dashed lines represent the experimental curves and the solid lines are for the LS-Dyna model. It should be noted that the magnitude of the forces are plotted for the comparison and the $\mathrm{Y}$ - force which is in the negative axis in the previous figures are shown in the positive axis along with the vertical force component. There is good comparison between the FE model and the experiment. Since there is no failure in the core for this trajectory, the horizontal component of the force ( $\mathrm{Y}$ - force) and the peak of the Z-force are simulated closely. The static friction constant of 0.3 in the contact between impactor and sandwich target was chosen to have this simulation. The oscillations in the force values from the simulation are a numerical artefact due to the contact algorithms. 


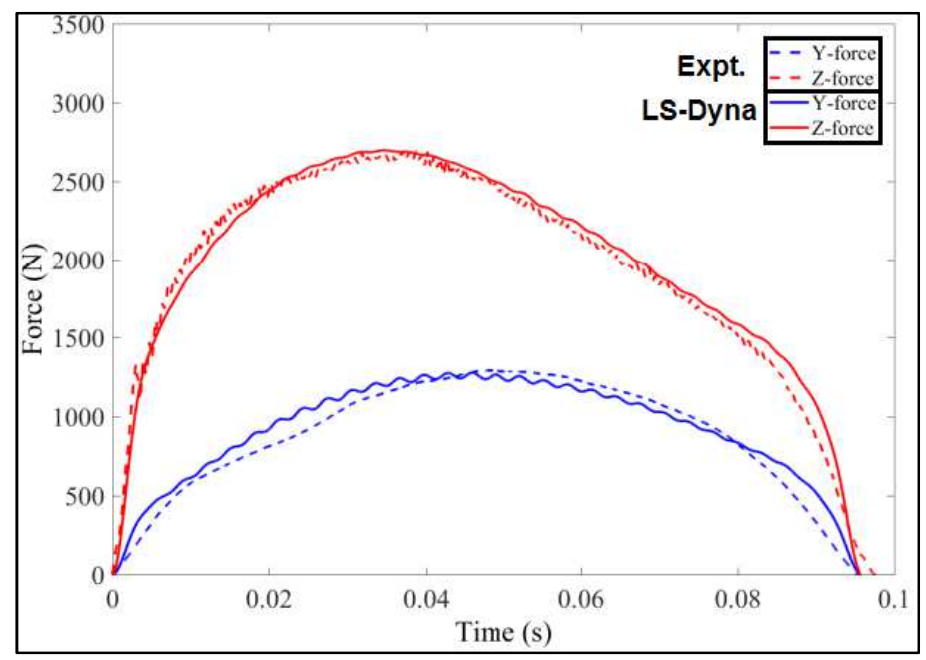

Figure 16 Comparison of Y-force and Z-force from experiment and LS-Dyna for Traj1 and cylindrical impactor

A speckled surface was created on the foam core facing the high speed camera using a spray can. A region of interest was selected in the high speed camera images that corresponds to the speckled surface of the foam core and Digital Image Correlation software Vic2D (Correlated Solutions) was used to obtain the strain history (principal and effective strains) from these speckle images. A comparison of the minimum principal strain contour at the end of the impact is shown in Figure 17. It can be seen that the minimum principal strain in the Rohacell core close to the point of contact is reproduced in the FE model. The experimental strain contour shows that a smaller thickness of the core undergoes deformation, and the FE results suggests that the localisation of the deformation in the core can be represented by the crushable foam model.

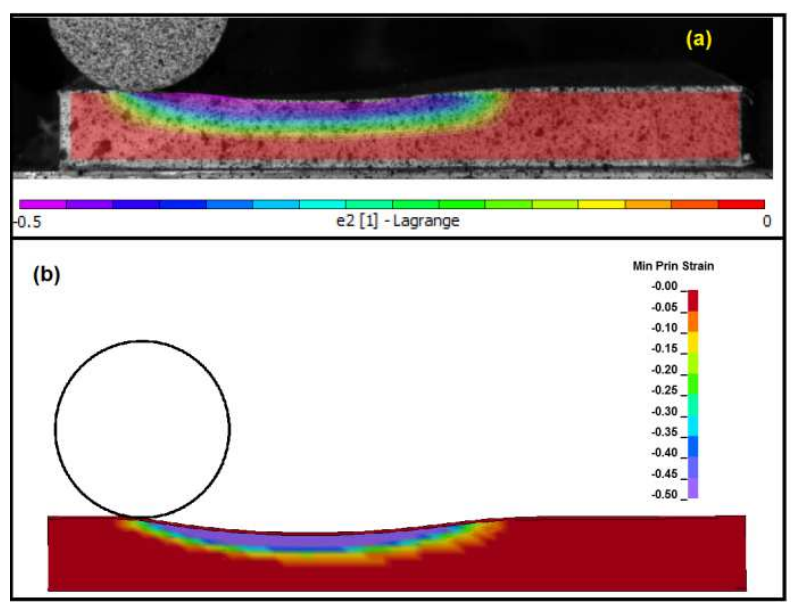

Figure 17 Comparison of Minimum principal strain history from Digital Image Correlation and LS-Dyna 
A comparison of the force- time histories in the horizontal and vertical directions for the parabolic trajectory with $50 \mathrm{~mm}$ opening and $8 \mathrm{~mm}$ depth (Traj2) centred on the plate, a friction coefficient of 0.3 and using several shapes of impactor are shown in the Figure18 for Kevlar Rohacell sandwich. It can be seen that the overall response of the sandwich panel obtained from the FE model is comparable to the experiment even though there are some marked differences between the two. The difference in the magnitude of the forces, for instance, are much larger than for the simulation of the Traj1 case, as the LS-Dyna model did not capture the different failure phenomena observed in the experiment. For instance, the drop in the Z-force observed for samples tested with the wedge shaped impactor correspond to the debonding failure between the sandwich and the support plate. This failure was not modelled and a perfect bonding was assumed for the LS-Dyna model. Similarly, the contact duration in the simulation is also adversely affected by the lack of failure modelling. The force- history for the sandwich panel without this failure mode (for Traj1) had a good correlation with experimental data.

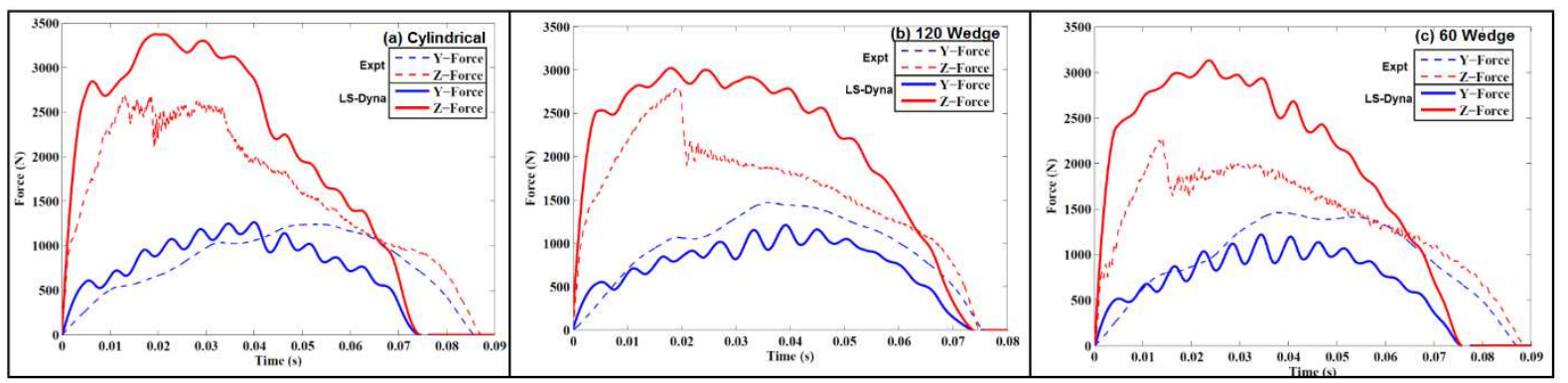

Figure 18 Comparison of force history from experiment and simulation for (a) Cylindrical impactor, (b) 120 Wedge and (c) 60 Wedge

One of the main reasons for the average quality of the comparison of simulation results and experiments is the assumption of perfect bonding between the sandwich plate and the aluminium support plate in the LS-Dyna model. In reality, there is debonding between the sandwich and the support plate during the impact as can be observed in Figure 14. The bonding of the sandwich plate to the aluminium sheet is necessitated by the clamping mechanism and attempts will be made to modify the fixture to avoid the failure of the adhesive layer. The study of the effect of the bonding strength between the sandwich plate and the support plate and the possibility of modelling this debonding failure is also proposed for future work. The modelling of the debonding is expected to appreciably improve the accuracy of the LS-Dyna model of parabolic impact. 
The contact duration is one of the most significant differences between the experiment and simulation. The duration of contact for the case of cylindrical impactor and $60^{\circ}$ wedge impactor in the Hexapod experiment are approximately 86 milliseconds while the duration is only 75 milliseconds in the simulation. It is supposed that the shear strain in the foam core is the cause of this discrepancy. There is also a larger region in the foam core just ahead of the impactor with permanent deformation in the LS-Dyna simulation. A limitation of the present FE model is the modelling of the shear behaviour of the foam core. Mosleh et al. [8] concluded that characterisation of cellular materials under multi-axial loading is necessary for the use of realistic and complex failure criteria in structural design, taking into account multiple loading directions. Lei et al. [29] found that the shear modulus of the foam was also critical in facesheet wrinkling in edgewise impact tests. The Crushable foam model used for the Rohacell foam uses uniaxial compression load curves for different strain rates. In the present material model available in LS-Dyna, this law does not include hydrostatic curves for calculating the volumetric part of the stress and strain. The model is primarily focussed on compression loading of the foam and multi-axial loading conditions are not reproduced accurately. Flores-Johnson et al.[30] and Mostafa et al. [31] have shown that a Crushable foam plasticity material model in ABAQUS can be used to model the shear behaviour of polymer foams, though the plasticity model fails to capture the brittle failure of the foam in tension. Serifi et al. [32] noted that the modelling of shear and tensile behaviour of foams in LS-Dyna using material models such as Crushable Foam and Fu Chang foam (MAT83) have certain limitations. A comparison of the shear response of EPP foam showed that the shear stiffness in the LS-Dyna model using MAT83 was lower than the experimental curves and that shear rupture was not captured in the model. Other material models such as the constitutive law proposed by Deshpande and Fleck which models the foam core as an isotropic porous solid with a principal stress- yield surface under compression and a quadratic- yield surface elsewhere in the stress space [33] may produce better comparison with experiments [34]. A physically based, multi-scale modelling approach incorporating stochastic aspects of the foam microstructure can also provide detailed predictions of all aspects of the mechanical response of foams but such a model doesn't exist presently [35] and the implementation of a comprehensive material law for the simulation of foams is left as a topic for a future study.

\section{Conclusions}


The study of the impact damage of sandwich panels has been limited to uni-directional impacts and there is a dearth of research on the mechanical behaviour of sandwich composites for complex trajectories. This paper describes the development of a novel method to conduct tri-dimensional impact tests on sandwich panels using a Hexapod. Parabolic impact tests were conducted on Kevlar Rohacell sandwich plates using the Hexapod. The effect of impactor shape was studied by comparing the response of the sandwich plate for impact with different impactor geometries, namely; cylindrical impactor, wedge impactors with angle of $120^{\circ}$ and $60^{\circ}$. The LS-Dyna model developed for the simulation of the low velocity impact of the Kevlar Rohacell sandwich plates were used to simulate the parabolic impacts. This serves to validate if the model developed for normal impact case can be used for other loading conditions. The force and displacement in vertical and horizontal directions were measured using the Hexapod and Digital Image Correlation was used to characterise surface shear strain field. The force histories and strain contours were compared with the FE simulations. The results of the FE model show reasonable correlation with experimental curves but the model was not able to capture the complex failure modes such as debonding and shear of foam core. Some limitations of the FE model have been identified and are recommended for future work. There are no standard testing methods available for this kind of impact and more experimental work is needed to establish clear protocols. The development of the Hexapod for tri-dimensional impact testing and the application of this setup for parabolic impact testing of Kevlar Rohacell sandwich plates is a first effort to investigate the complex behaviour of sandwich composites in real loading situations.

Data availability statement: The raw/processed data required to reproduce these findings cannot be shared at this time as the data also forms part of an ongoing study.

\section{References}

[1] Caliskan U, Apalak MK. Low velocity bending impact behavior of foam core sandwich beams: Experimental. Compos Part B Eng 2017;112:158-75. doi:10.1016/j.compositesb.2016.12.038.

[2] Chai GB, Zhu S. A review of low-velocity impact on sandwich structures. Proc Inst Mech Eng Part L J Mater Des Appl 2011;225:207-30. doi:10.1177/1464420711409985.

[3] Hampson PR, Moatamedi M. A review of composite structures subjected to dynamic loading. Int J Crashworthiness 2007;12:411-28. doi:10.1080/13588260701483334.

[4] Ramakrishnan KR, Guérard S, Viot P, Shankar K. Effect of block copolymer nanoreinforcements on the low velocity impact response of sandwich structures. Compos Struct 2014;110:174-82. doi:10.1016/j.compstruct.2013.12.001.

[5] Ivañez I, Moure MM, Garcia-Castillo SK, Sanchez-Saez S. The oblique impact response of composite sandwich plates. Compos Struct 2015;133:1127-36. doi:10.1016/j.compstruct.2015.08.035. 
[6] Sutherland LS. A review of impact testing on marine composite materials: Part I - Marine impacts on marine composites. Compos Struct 2018;188:197-208. doi:10.1016/j.compstruct.2017.12.073.

[7] Zhu L, Liu W, Fang H, Chen J, Zhuang Y, Han J. Design and simulation of innovative foamfilled Lattice Composite Bumper System for bridge protection in ship collisions. Compos Part B Eng 2019;157:24-35. doi:10.1016/j.compositesb.2018.08.067.

[8] Mosleh Y, Vanden Bosche K, Depreitere B, Vander Sloten J, Verpoest I, Ivens J. Effect of polymer foam anisotropy on energy absorption during combined shear-compression loading. $\mathrm{J}$ Cell Plast 2018;54:597-613. doi:10.1177/0021955X17720156.

[9] Navarro P, Aubry J, Marguet S, Ferrero JF, Lemaire S, Rauch P. Experimental and numerical study of oblique impact on woven composite sandwich structure: Influence of the firing axis orientation. Compos Struct 2012;94:1967-72. doi:10.1016/j.compstruct.2012.02.001.

[10] Birman V, Kardomateas GA. Review of current trends in research and applications of sandwich structures. Compos Part B Eng 2018;142:221-40. doi:10.1016/j.compositesb.2018.01.027.

[11] Zhou J, Hassan MZ, Guan Z, Cantwell WJ. The low velocity impact response of foam-based sandwich panels. Compos Sci Technol 2012;72:1781-90. doi:10.1016/j.compscitech.2012.07.006.

[12] Goswami S, Becker W. The effect of facesheet/core delamination in sandwich structures under transverse loading. Compos Struct 2001;54:515-21. doi:10.1016/S0263-8223(01)00124-6.

[13] Ma P, Zhang F, Gao Z, Jiang G, Zhu Y. Transverse impact behaviors of glass warp-knitted fabric/foam sandwich composites through carbon nanotubes incorporation. Compos Part B Eng 2014;56:847-56. doi:10.1016/j.compositesb.2013.09.013.

[14] Guérard S, Barou J-L, Mahéo L, Viot P. Development of a new experimental device for tridimensional impacts - Results on foam-core sandwich panels -. ICILLS - Capet., 2014, p. 36.

[15] Ramakrishnan KR, Guérard S, Maheo L, Shankar K, Viot P. Development of a Finite Element Model for the simulation of parabolic impact of sandwich panels. EPJ Web Conf 2015;94:1018. doi:DOI: 10.1051/epjconf/20159401018.

[16] Kurşun A, Şenel M, Enginsoy HM, Bayraktar E. Effect of impactor shapes on the low velocity impact damage of sandwich composite plate: Experimental study and modelling. Compos Part B Eng 2016;86:143-51. doi:10.1016/j.compositesb.2015.09.032.

[17] Mackerle J. Finite element analyses of sandwich structures: a bibliography (1980-2001). Eng Comput 2002;19:206-45. doi:10.1108/02644400210419067.

[18] Nemes JA, Simmonds KE. Low-Velocity Impact Response of Foam-Core Sandwich Composites. J Compos Mater 1992;26:500-19. doi:10.1177/002199839202600403.

[19] Rajaneesh A, Sridhar I, Rajendran S. Impact modeling of foam cored sandwich plates with ductile or brittle faceplates. Compos Struct 2012;94:1745-54. doi:10.1016/j.compstruct.2011.12.021.

[20] Morada G, Ouadday R, Vadean A, Boukhili R. Low-velocity impact resistance of ATH/epoxy core sandwich composite panels: Experimental and numerical analyses. Compos Part B Eng 2017;114:418-31. doi:10.1016/j.compositesb.2017.01.070.

[21] Feng $D$, Aymerich $F$. Finite element modelling of damage induced by low-velocity impact on composite laminates. Compos Struct 2014;108:161-71. doi:10.1016/j.compstruct.2013.09.004.

[22] Wang $\mathrm{H}$, Ramakrishnan KR, Shankar K. Experimental study of the medium velocity impact response of sandwich panels with different cores. Mater Des 2016;99:68-82. doi:10.1016/j.matdes.2016.03.048.

[23] Chen Y, Hou S, Fu K, Han X, Ye L. Low-velocity impact response of composite sandwich structures: Modelling and experiment. Compos Struct 2017;168:322-34. doi:10.1016/j.compstruct.2017.02.064.

[24] Pascal F, Rogani A, Mahmoud B, Navarro P, Marguet S, Ferrero JF. Impact damage 
prediction in thin woven composite laminates - Part II: Application to normal and oblique impacts on sandwich structure. Compos Struct 2018;190:43-51. doi:10.1016/j.compstruct.2018.02.013.

[25] Ramakrishnan KR, Denneulin S, Guérard S, Shankar K, Viot P. Finite element modelling of the low velocity impact response of composite plates with block copolymer. Int J Automot Compos 2016;2:3-22.

[26] Denneulin S. Etude du comportement dynamique de matériaux composites sous sollicitations de chocs- Application à un casque aeronautique. PhD Thesis. Ecole Nationale Supérieure d'Arts et Métiers; 2011.

[27] Li QM, Mines RAW, Birch RS. The crush behaviour of Rohacell-51WF structural foam. Int J Solids Struct 2000;37:6321-41. doi:10.1016/S0020-7683(99)00277-2.

[28] Dogan F, Hadavinia H, Donchev T, Bhonge PS. Delamination of impacted composite structures by cohesive zone interface elements and tiebreak contact. Cent Eur $\mathrm{J}$ Eng 2012;2:612-26. doi:10.2478/s13531-012-0018-0.

[29] Lei H, Yao K, Wen W, Zhou H, Fang D. Experimental and numerical investigation on the crushing behavior of sandwich composite under edgewise compression loading. Compos Part B Eng 2016;94:34-44. doi:10.1016/j.compositesb.2016.03.049.

[30] Flores-Johnson EA, Li QM, Mines RAW. Degradation of Elastic Modulus of ProgressivelyCrushable Foams in Uniaxial Compression. J Cell Plast 2008;44:415-34. doi:10.1177/0021955X08095113.

[31] Mostafa A, Shankar K, Morozov E V. Insight into the shear behaviour of composite sandwich panels with foam core. Mater Des 2013;50:92-101. doi:10.1016/j.matdes.2013.03.016.

[32] Serifi E, Hirth A, Matthaei S, Mullerschon H. Modelling of Foams using MAT83 - Preparation and Evaluation of eperimental data. 4th Eur LSDYNA Users Conf 2003:59-72.

[33] LS-DYNA Manual I. Keywords user's manual I 2012;I.

[34] Donnard A, Guérard S, Maheo L, Viot P, Rio G. Multiaxial experiments with radial loading paths on a polymeric foam. Polym Test 2018;67:441-9. doi:10.1016/j.polymertesting.2018.03.003.

[35] Arezoo S, Tagarielli VL, Petrinic N, Reed JM. The mechanical response of Rohacell foams at different length scales. J Mater Sci 2011;46:6863-70. doi:10.1007/s10853-011-5649-7. 